\title{
Wearing high heels with an appropriate height is protective for pelvic floor function
}

\author{
Yangyun Wang ${ }^{1} \wedge$, Chaoliang Shi ${ }^{1}$, Wei Jiao ${ }^{1}$, Wandong Yu ${ }^{1}$, Guowei Shi ${ }^{1}$, Junhua Zheng ${ }^{2}$ \\ ${ }^{1}$ Department of Urology, The Fifth People's Hospital of Shanghai, Fudan University, Shanghai, China; ${ }^{2}$ Department of Urology, Shanghai Renji \\ Hospital, Shanghai, China; \\ Contributions: (I) Conception and design: All authors; (II) Administrative support: G Shi, Y Wang; (III) Provision of study materials or patients: \\ Y Wang, C Shi; (IV) Collection and assembly of data: All authors; (V) Data analysis and interpretation: All authors; (VI) Manuscript writing: All \\ authors; (VII) Final approval of manuscript: All authors. \\ Correspondence to: Junhua Zheng. Department of Urology, Shanghai Renji Hospital, Shanghai, China. Email: zhengjh0471@sina.com; Guowei Shi. \\ Department of Urology, The Fifth People's Hospital of Shanghai, Fudan University, Shanghai, China. Email: dr.sgw@189.cn.
}

\begin{abstract}
Background: Wearing high-heeled shoes is a common phenomenon among women. However, the association between wearing high heels and pelvic floor function is largely unknown. Our aim was to evaluate the effects of wearing different height shoes on pelvic floor function and to analyze the influencing factors.

Methods: This was a population-based, cross-sectional study performed in general hospitals with a pelvic floor subspecialty in some cities of China. All participants completed a Urogenital Distress Inventory (UDI-6) questionnaire that consisted of demographic data, information about wearing shoes, and information about pelvic floor function (UDI-6). One-way ANOVA was carried out to compare the differences among 4 groups according to the heel height ( $<3,3-5,5-7$, and $>7 \mathrm{~cm}$ groups). Multivariate logistic regression was performed to identify the factors influencing the effect of wearing 3-5 cm high-heeled shoes on pelvic floor function.
\end{abstract}

Results: In total, 1,263 participants finished the questionnaire and full data were collected. The 4 groups were comparable for clinical data, and participants who wore $3-5 \mathrm{~cm}$ high-heeled shoes had the lowest UDI6 scores. Multivariate analysis revealed that the number of hours ( $\geq 8 \mathrm{~h}$ ) wearing high heels per day and the thickness diameter $(\geq 3 \mathrm{~cm})$ of the heel were important factors affecting the protective effect of wearing $3-5 \mathrm{~cm}$ high-heeled shoes on pelvic floor function.

Conclusions: Wearing heeled shoes with a $3-5 \mathrm{~cm}$ heel height and $\geq 3 \mathrm{~cm}$ thickness for a long period of time is good for the pelvic floor function of women.

Keywords: Pelvic floor dysfunction (PFD); high heel; pelvic floor muscle training (PFM training)

Submitted Apr 14, 2021. Accepted for publication Jun 17, 2021.

doi: $10.21037 /$ tau-21-486

View this article at: https://dx.doi.org/10.21037/tau-21-486

\section{Introduction}

Pelvic floor dysfunction (PFD) describes the medical situations related to changes within the pelvic floor, including urinary incontinence, bladder and bowel disorders, pelvic organ prolapse, sexual dysfunction, and pelvic pain (1). These conditions are widely predominant, particularly among females, and have an impact on quality of life and have important socioeconomic implications (2). The female pelvic floor is a complicated unit responsible for numerous functions besides pelvic organ support. It consists of all the structures in the bony pelvis: the pelvic floor muscles (PFMs), connective tissues, nerves, blood vessels,

^ ORCID: 0000-0003-4757-3722. 
and urogenital and anorectal viscera (3). The PFMs form a diaphragm that spans the whole pelvic hollow space and incorporates the coccygeus and levator ani muscle groups. The levator ani muscle provides support to all of the pelvic floor organs and is transversed by the urethra, vagina, and anus. Because the levator ani muscles provide support to all 3 organ systems, their weakness will result in impaired function of any, or all, of the structures that the muscles support. The levator ani muscles consist of type I muscle fibers, which maintain the constant muscle tone necessary to keep the urogenital hiatus closed (4). Notably, the activity of PFMs can be influenced by different body positions and lumbopelvic posture $(5,6)$.

Wearing high heels is a common habit in women to appear slender and taller. It is reported that $37-69 \%$ of ladies prefer to wear high-heeled shoes daily (7). However, wearing high heels may cause several deleterious effects on the back, knees, and lower leg pain (8). In addition, high heels can impact foot arches. Because high heels cause tendons to weaken and do not properly support the feet, women who wear high heels are at risk, especially those who spend extensive amounts of time standing up $(9,10)$. Moreover, as heel height increases from 3 to $7 \mathrm{~cm}$, peak pressure and shear stress have been found to shift from the lateral to the medial forefoot during both standing and walking (11). Due to the potential consequences of slips and falls, it is recommended that the best heel height for the maintenance of balance is from 3 to $5 \mathrm{~cm}(12-14)$, which is a comfortable height with a good impact on women's appearance. In addition, wearing high-heeled shoes is found to have an impact on the rotational motion of the ankle complex during walking (15), and different ankle positions can alter PFM activity (16). The association between wearing high heels and pelvic floor function has not been fully clarified. Additionally, whether a heel height of 3 to $5 \mathrm{~cm}$ is protective to women's pelvic floor is largely unknown.

Given the influence of high-heeled shoes on ankle position and the association between ankle position and PFM activity, it is of significance to investigate the effect of different heights of shoes on PFM activity. The objectives of this study were: (I) to evaluate the effects of wearing shoes with different heel heights on PFM function using population-based questionnaire research; and (II) to analyze the factors influencing the effects of wearing $3-5 \mathrm{~cm}$ highheeled shoes on PFM function. We present the following article in accordance with the STROBE reporting checklist (available at https://dx.doi.org/10.21037/tau-21-486).

\section{Methods}

\section{Study design}

This was a population-based, cross-sectional study performed in general hospitals with a pelvic floor subspecialty in some cities of China, including Shanghai First People's Hospital, Shanghai Fifth People's Hospital, Renji Hospital, Huadong Hospital Affiliated to Fudan University, Changhai Hospital, and the First Hospital of Shanxi Medical University. The inclusion criteria were age $\geq 18$ years and female. The exclusion criteria were limp, pelvic surgery history, and cognitive impairment.

All participants who met the above criteria were interviewed to complete a questionnaire that consisted of 3 parts: (I) demographic information: age, height, weight, parity, and delivery pattern; (II) information about wearing shoes: how many times do you wear heeled shoes per week? How many hours do you wear heeled shoes per day? What is the height of the heel that you regularly wear? What is the heel thickness (the maximum diameter of the heel in contact with the ground) that you regularly wear? (III) information about pelvic floor function: Urogenital Distress Inventory (UDI-6) is a validated 6-item questionnaire that evaluates lower urinary tract symptoms in women (17). The UDI-6 provides a score ranging from $0-100$, with a higher score reflecting a greater severity of symptoms. The study was conducted in accordance with the Declaration of Helsinki (as revised in 2013). The study was approved by the Institutional Review Board of The Fifth People's Hospital of Shanghai, Fudan University (No.: WY-2020139) and written informed consent was obtained from all patients.

\section{Statistical analysis}

Descriptive data were provided for the all participants and per group. Statistical analyses were performed using SPSS Statistics 25 (SPSS Inc., Chicago, IL, USA). Categorical variables were displayed as $\mathrm{n}(\%)$. Quantitative data were shown as mean \pm standard deviation $(\mathrm{SD})$. Oneway ANOVA was carried out to compare the differences among multiple groups. Multivariate logistic regression was performed to identify the important factors influencing the effect of wearing 3-5 cm high-heeled shoes on pelvic floor function. Odds ratios (ORs) and 95\% confidence intervals (CIs) were calculated for estimation. A value of $\mathrm{P}<0.05$ was considered statistically significant. 
Table 1 Clinical characteristics of all participants

\begin{tabular}{|c|c|}
\hline Characteristics & Data \\
\hline Age (years) & $39.61 \pm 11.37$ \\
\hline $20-29$ & 206 (16.31) \\
\hline 30-39 & $619(49.01)$ \\
\hline $40-49$ & $164(12.98)$ \\
\hline $50-59$ & $146(11.56)$ \\
\hline$\geq 60$ & $128(10.13)$ \\
\hline $\mathrm{BMI}\left(\mathrm{kg} / \mathrm{m}^{2}\right)$ & $22.24 \pm 3.45$ \\
\hline Underweight $(<18.5)$ & 199 (15.76) \\
\hline Normal (18.5-23.9) & $684(54.16)$ \\
\hline Overweight (24-27.9) & $324(25.65)$ \\
\hline Obese (>28) & $56(4.43)$ \\
\hline \multicolumn{2}{|l|}{ Parity (n) } \\
\hline 0 & $101(8.00)$ \\
\hline 1 & $646(51.15)$ \\
\hline 2 & $458(36.26)$ \\
\hline$\geq 3$ & $58(4.59)$ \\
\hline \multicolumn{2}{|l|}{ Delivery pattern } \\
\hline Nulliparous & $101(8.00)$ \\
\hline Vaginal delivery & $827(65.48)$ \\
\hline Cesarean section & $335(26.52)$ \\
\hline
\end{tabular}

\section{Results}

In total, 1,263 participants finished the questionnaire and full data were collected. The clinical characteristics are presented in Table 1. The age was $39.61 \pm 11.37$ years and BMI was $22.24 \pm 3.45 \mathrm{~kg} / \mathrm{m}^{2}$.

Because 3-5 cm is the best heel height for the maintenance of balance, the participants were divided into 4 groups according to their heel height: $<3,3-5,5-7$, and $>7 \mathrm{~cm}$ groups. As shown in Table 2, 427 (33.80\%), 477 (37.77\%), $246(19.48 \%)$, and $113(8.95 \%)$ participants wore shoes with heel height $<3,3-5,5-7$, and $>7 \mathrm{~cm}$, respectively. Compared to participants in the $3-5 \mathrm{~cm}$ group, the participants in the $<3 \mathrm{~cm}$ group were older $(\mathrm{P}<0.05)$, but there was no significant difference in age in the participants in the $5-7 \mathrm{~cm}$ and $>7 \mathrm{~cm}$ groups $(\mathrm{P}>0.05)$. Meanwhile, only the BMI of participants in the $<3 \mathrm{~cm}$ group was higher than that of the $3-5 \mathrm{~cm}$ group $(\mathrm{P}<0.05)$. No significant differences existed in parity among the 4 groups $(\mathrm{P}<0.05)$.
These data indicated that the 4 groups were comparable for clinical data. Notably, the UDI-6 score of participants in the $3-5 \mathrm{~cm}$ group was the lowest among the 4 groups with a significant difference $(\mathrm{P}<0.05)$, indicating that wearing $3-5 \mathrm{~cm}$ high-heeled shoes might be protective for pelvic floor function. We then analyzed the factors influencing the effects of wearing $3-5 \mathrm{~cm}$ high-heeled shoes on pelvic floor function, including the number of days wearing high heels per week, the number of hours wearing high heels per day, and heel thickness (diameter). The results demonstrated that wearing 3-5 cm high-heeled shoes more than $8 \mathrm{~h}$ per day (8-12 h, OR: 3.238, 95\% CI: 1.520-6.899, P=0.002; $>12$ h, OR: $2.734,95 \%$ CI: $1.252-5.968, \mathrm{P}=0.012)$ and heel thickness (diameter) $\geq 3 \mathrm{~cm}$ ( $3 \mathrm{~cm}$, OR: $2.590,95 \%$ CI: 1.115-6.020, $\mathrm{P}=0.027$; $>3$ cm, OR: $2.968,95 \%$ CI: 1.210 7.280, $\mathrm{P}=0.017$ ) were protective factors for pelvic floor function $(\mathrm{P}<0.05)$ (Table 3).

\section{Discussion}

With the change in aesthetics, many young women want to look taller and more fashionable, preferring to wear high-heeled shoes during their daily lives. However, wearing high-heeled shoes with an excessive focus on design or fashion may increase the risk of falls and result in various musculoskeletal disorders and deformities $(18,19)$. In addition, wearing high-heeled shoes influences the rotational motion of the ankle complex during walking (15), and the ankle position is found to be related to the pelvis inclination and PFM activation (16). Whether there is an association between wearing high heels and PFM activity has not been fully investigated.

In the present study, we investigated the influence of wearing shoes of different heights on pelvic floor function evaluated by the UDI- 6 score, and analyzed the potential risk factors affecting pelvic floor function, such as the length of time heeled-shoes are worn and the thickness diameter of the heels. Our results showed that the 4 groups were comparable for clinical data, and wearing $3-5 \mathrm{~cm}$ highheeled shoes might be protective for pelvic floor function. Furthermore, multivariate analysis revealed that the number of hours ( $\geq 8 \mathrm{~h}$ ) wearing high heels per day and the thickness diameter $(\geq 3 \mathrm{~cm})$ of the heel were related to a significantly lower UDI-6 score. To our knowledge, this is the first study with a large sample size (1,263 female participants) for the analysis of the effect of wearing high heels on PFM function in a population-based survey. Our findings will provide reliable data to guide clinical practice. 
Table 2 Clinical characteristics of participants in different heel height groups

\begin{tabular}{lcccc}
\hline Characteristics & $<3 \mathrm{~cm}$ & $3-5 \mathrm{~cm}$ & $5-7 \mathrm{~cm}$ & $>7 \mathrm{~cm}$ \\
\hline Patients, $\mathrm{n}(\%)$ & $427(33.80)$ & $477(37.77)$ & $246(19.48)$ & $113(8.95)$ \\
Age (years) & $39.69 \pm 11.36^{*}$ & $38.29 \pm 10.33$ & $36.29 \pm 8.83$ & $36.61 \pm 8.73$ \\
BMl $\left(\mathrm{kg} / \mathrm{m}^{2}\right)$ & $22.26 \pm 3.45^{\star}$ & $21.83 \pm 3.07$ & $22.41 \pm 3.64$ & $21.27 \pm 3.26$ \\
Parity $(\mathrm{n})$ & $1.38 \pm 0.70$ & $1.37 \pm 0.76$ & $1.25 \pm 0.59$ & $1.33 \pm 0.56$ \\
UDI-6 score & $28.68 \pm 21.21^{*}$ & $19.90 \pm 17.49$ & $33.25 \pm 18.36^{\star}$ & $32.79 \pm 20.94^{*}$ \\
\hline
\end{tabular}

*, indicates $\mathrm{P}<0.05$ when compared to the $3-5 \mathrm{~cm}$ group.

Table 3 Multivariate logistic regression for the factors influencing the effect of wearing $3-5 \mathrm{~cm}$ high-heeled shoes on pelvic floor function

\begin{tabular}{|c|c|c|c|}
\hline Variables & $\mathrm{n} /$ total & OR $(95 \% \mathrm{Cl})$ & $P$ value \\
\hline \multicolumn{4}{|c|}{ The number of days wearing high heels per week } \\
\hline$<1 \mathrm{~d}$ & $10 / 477$ & 1.00 & \\
\hline $1-2 d$ & $208 / 477$ & $0.521(0.119-2.275)$ & 0.386 \\
\hline $3-4 d$ & $124 / 477$ & $1.012(0.230-4.459)$ & 0.988 \\
\hline \multicolumn{4}{|c|}{ The number of hours wearing high heels per day } \\
\hline$<2 \mathrm{~h}$ & $73 / 477$ & 1.00 & \\
\hline $3-5 \mathrm{~h}$ & $135 / 477$ & $1.090(0.059-2.243)$ & 0.815 \\
\hline $6-8 \mathrm{~h}$ & $130 / 477$ & $1.226(0.598-2.514)$ & 0.578 \\
\hline \multicolumn{4}{|c|}{ Heel thickness (diameter) } \\
\hline $1 \mathrm{~cm}$ & $47 / 477$ & 1.00 & \\
\hline $2 \mathrm{~cm}$ & $184 / 477$ & $1.313(0.558-3.091)$ & 0.533 \\
\hline $3 \mathrm{~cm}$ & $161 / 477$ & $2.590(1.115-6.020)$ & 0.027 \\
\hline$>3 \mathrm{~cm}$ & $85 / 477$ & $2.968(1.210-7.280)$ & 0.017 \\
\hline
\end{tabular}

PFM function plays a decisive role in maintaining urinary continence and pelvic organ support (20). PFMs are composed of $70 \%$ slow-twitch (type I) and $30 \%$ fast-twitch (type II) fibers (21). Type I muscle fibers are primarily responsible for PFM endurance, and maintain the constant muscle tone necessary to keep the urogenital hiatus closed (4). Although they fatigue faster than type I fibers, type II fibers are primarily responsible for PFM strength and power, which prevent urinary leakage during sudden actions (22). PFMs are revealed to impact important functions in urethral closure at rest and the intraabdominal pressure increases during exertion (e.g., sneezing or exercise) (23). PFM training is widely used for the treatment and prevention of PFD (24), and the possible mechanisms are: (I) that women develop a "knack" for consciously contracting PFMs before and during abdominal pressure increases during exertion, and (II) that strengthening the PFMs can establish the structural support to the pelvic floor (25). In our study, wearing shoes with a $3-5 \mathrm{~cm}$ heel height and $\geq 3 \mathrm{~cm}$ thickness for more than $8 \mathrm{~h}$ per day, including walking, standing, and sitting positions, might be an approach for PFM training: when PFMs contract, it causes the inhibition of detrusor overactivity; when the PFMs and the external sphincter of the urethra contract, 
the relaxation of the internal sphincter of the urethra is inhibited, and urine cannot enter the posterior urethra, thus terminating urination. This may be a potential mechanism regulating the protective effect of wearing high heels on pelvic floor function.

In addition, the pelvic tilt angle caused by the change in ankle movement is an important factor influencing PFM activity $(26,27)$. When wearing heeled shoes, the ankle is unstable plantar flexion and may result in greater PFM activity in the standing position. With high-heeled shoes, the pelvis tilts more posteriorly, inducing a compensatory posture with gluteal contraction (28). It suggests that PFM contraction in active ankle positions results in the simultaneous use of abdominal, back, thigh, and leg muscles to maintain posture. The co-activation of abdominal muscles and the pelvic floor is of importance in PFD and should be considered in rehabilitation programs. Chen et al. demonstrated that an upright standing posture with the ankles dorsiflexed could facilitate anterior pelvic tilt, which in turn increased effective PFM activity to its greatest point (29). Moreover, it has been suggested to use various ankle positions to try to improve the success rate of PFM training (30). The ankle position induced by wearing highheeled shoes might have an impact on PFM activity due not only to the posterior pelvic tilt but also the higher impact force transmitted to the PFMs (31). Notably, changes in the distribution of foot pressure and displacement of the center of pressure were not significantly altered after walking in middle-heeled $(4 \mathrm{~cm})$ shoes, but were remarkably altered after walking in either flat $(0.5 \mathrm{~cm})$ or high-heeled $(9 \mathrm{~cm})$ shoes, confirming that middle-heeled $(4 \mathrm{~cm})$ shoes are good for the health and comfort of the feet (32). In this study, we enrolled a larger number of patients and found that wearing 3-5 $\mathrm{cm}$ high-heeled shoes was related to a significantly lower UDI-6 score, which may explain why 3-5 cm height may be suitable for ankles, pelvis, and spine. Moreover, Lee et al. reported that heel thickness is related to walking stability (33). Our results showed that heel thickness (diameter) $\geq 3 \mathrm{~cm}$ was a protective factor for pelvic floor function, which may be associated with a relatively stable plantar flexion caused by good stability. However, our results were not consistent with previous findings that no significant link was identified among wearing high heels, anal canal pressure values, and the severity of fecal incontinence by the Wexner scale (34). More studies are still required to confirm our findings.

There are also some limitations meriting further consideration. One limitation of this study was that pelvic floor function was only evaluated by collecting the UDI-6 questionnaire from participants. More objective measurements should be taken, such as PFM strength (Modified Oxford Scale), intrapelvic surface electromyography of PFMs, and ultrasound imaging of the pelvic floor. Another limitation was that we only collected data on the time that women wore heeled shoes, and it was not clear that they spent most of their time standing or sitting. Because body position is also an important factor influencing PFM function (6,35), collecting the accurate time wearing heeled shoes in the standing position may be more meaningful than the method in the current research.

\section{Conclusions}

This study showed that wearing shoes with a $3-5 \mathrm{~cm}$ heel height and $\geq 3 \mathrm{~cm}$ thickness for more than $8 \mathrm{~h}$ per day was protective for the pelvic floor function of women. Because pelvic tilt may vary according to age and the habit of walking with high heels, further studies are necessary.

\section{Acknowledgments}

Funding: The Shanghai Key Medical Specialty Program (No. ZK2019A03); Scientific research project of Shanghai Municipal Health and Family Planning Commission (201940006); Hospital-level project of Shanghai Fifth People's Hospital (2019WYZT02).

\section{Footnote}

Reporting Checklist: The authors have completed the STROBE reporting checklist. Available at https://dx.doi. org/10.21037/tau-21-486

Data Sharing Statement: Available at https://dx.doi. org/10.21037/tau-21-486

Conflicts of Interest: All authors have completed the ICMJE uniform disclosure form (available at https://dx.doi. org/10.21037/tau-21-486). The authors have no conflicts of interest to declare.

Ethical Statement: The authors are accountable for all aspects of the work in ensuring that questions related to the accuracy or integrity of any part of the work are appropriately investigated and resolved. The study was conducted in accordance with the Declaration of Helsinki 
(as revised in 2013). The study was approved by the Institutional Review Board of The Fifth People's Hospital of Shanghai, Fudan University (No.: WY-2020-139) and written informed consent was obtained from all patients.

Open Access Statement: This is an Open Access article distributed in accordance with the Creative Commons Attribution-NonCommercial-NoDerivs 4.0 International License (CC BY-NC-ND 4.0), which permits the noncommercial replication and distribution of the article with the strict proviso that no changes or edits are made and the original work is properly cited (including links to both the formal publication through the relevant DOI and the license). See: https://creativecommons.org/licenses/by-nc-nd/4.0/.

\section{References}

1. Bo K, Frawley HC, Haylen BT, et al. An International Urogynecological Association (IUGA)/International Continence Society (ICS) joint report on the terminology for the conservative and nonpharmacological management of female pelvic floor dysfunction. Int Urogynecol J 2017;28:191-213.

2. Colla C, Paiva LL, Ferla L, et al. Pelvic floor dysfunction in the immediate puerperium, and 1 and 3 months after vaginal or cesarean delivery. Int J Gynaecol Obstet 2018;143:94-100.

3. Dumoulin C, Pazzoto Cacciari L, Mercier J. Keeping the pelvic floor healthy. Climacteric 2019;22:257-62.

4. A. Ashton-Miller DH, John OL Delancey, James. The functional anatomy of the female pelvic floor and stress continence control system. Scan J Urol Nephrol 2001;35:1-7.

5. Capson AC, Nashed J, Mclean L. The role of lumbopelvic posture in pelvic floor muscle activation in continent women. J Electromyogr Kinesiol 2011;21:166-77.

6. Chmielewska D, Stania M, Sobota G, et al. Impact of different body positions on bioelectrical activity of the pelvic floor muscles in nulliparous continent women. Biomed Res Int 2015;2015:905897.

7. Cronin NJ. The effects of high heeled shoes on female gait: a review. J Electromyogr Kinesiol 2014;24:258-63.

8. Wadee AN. Influence of Wearing High Heel on Different Foot Angels in Normal Female. Med J Cairo Univ 2017;85:811-7.

9. Yung-Hui L, Wei-Hsien H. Effects of shoe inserts and heel height on foot pressure, impact force, and perceived comfort during walking. Appl Ergon 2005;36:355-62.
10. D'Août K, Meert L, Van Gheluwe B, et al. Experimentally generated footprints in sand: analysis and consequences for the interpretation of fossil and forensic footprints. Am J Phys Anthropol 2010;141:515-25.

11. Cong Y, Cheung JTM, Leung AK, et al. Effect of heel height on in-shoe localized triaxial stresses. J Biomech 2011;44:2267-72.

12. Ko DY, Lee HS. The changes of COP and foot pressure after one hour's walking wearing high-heeled and flat shoes. J Phys Ther Sci 2013;25:1309-12.

13. Ryu JS. Effects of high-heeled shoe with different height on the balance during standing and walking. Korean J Sport Biomechanics 2010;20:479-86.

14. Lee GC, Jeong HM, Kim SB, et al. Effects of the differences in shoe heel-height on balanced performances. J Korean Phys Ther 2004;16:112-24.

15. Wang C, Geng X, Wang S, et al. The impact of highheeled shoes on ankle complex during walking in young women - In vivo kinematic study based on 3D to $2 \mathrm{D}$ registration technique. J Electromyogr Kinesiol 2016;28:7-16.

16. Kannan P, Winser S, Goonetilleke R, et al. Ankle positions potentially facilitating greater maximal contraction of pelvic floor muscles: A systematic review and metaanalysis. Disability Rehabilitation 2019;41:2483-91.

17. Lemack GE, Zimmern PE. Predictability of urodynamic findings based on the Urogenital Distress Inventory- 6 questionnaire. Urology 1999;54:461-6.

18. Nawaz U, Hashmi MA, Qureshi MY, et al. Prevalence of musculoskeletal pain among young females using different heel heights: a cross-sectional study. Rawal Med J 2019;44:220-2.

19. Qureshi MY, Akbar B. A Cross-Sectional Study Determining Pain in Lower Back and Calf Muscles among Females Due to High Heel Shoe Wear. Health Sci 2019;8:70-4.

20. Dumoulin C, Le Berre M. Pelvic Floor Muscle Training for Older Women with Urinary Incontinence. JAMA Intern Med 2020:1284-93.

21. Hwang UJ, Lee MS, Jung SH, et al. Which pelvic floor muscle functions are associated with improved subjective and objective symptoms after 8 weeks of surface electrical stimulation in women with stress urinary incontinence? Eur J Obstet Gynecol Reprod Biol 2020;247:16-21.

22. Milios JE, Atkinson CL, Naylor LH, et al. Pelvic floor muscle assessment in men post prostatectomy: comparing digital rectal examination and real-time ultrasound approaches. Australian New Zealand Continence J 
2018;24:105.

23. Dompeyre P, Fritel X, Fauconnier A, et al. Pelvic floor muscle contraction and maximum urethral closure pressure. Progres en urologie 2015;25:200-5.

24. Bø K. Can pelvic floor muscle training prevent and treat pelvic organ prolapse? Acta obstetricia et gynecologica Scandinavica 2006;85:263-8.

25. Culligan PJ, Scherer J, Dyer K, et al. A randomized clinical trial comparing pelvic floor muscle training to a Pilates exercise program for improving pelvic muscle strength. Int Urogynecol J 2010;21:401-8.

26. Lee K. Investigation of Electromyographic Activity of Pelvic Floor Muscles in Different Body Positions to Prevent Urinary Incontinence. Med Sci Monit 2019;25:9357.

27. Ptaszkowski K, Zdrojowy R, Slupska L, et al. Assessment of bioelectrical activity of pelvic floor muscles depending on the orientation of the pelvis in menopausal women with symptoms of stress urinary incontinence: continued observational study. Eur J Phys Rehabil Med 2017;53:564-74.

28. Russell BS. The effect of high-heeled shoes on lumbar lordosis: a narrative review and discussion of the disconnect between Internet content and peer-reviewed literature. J Chiropr Med 2010;9:166-73.

Cite this article as: Wang Y, Shi C, Jiao W, Yu W, Shi G, Zheng J. Wearing high heels with an appropriate height is protective for pelvic floor function. Transl Androl Urol 2021;10(6):2493-2499. doi: 10.21037/tau-21-486
29. Chen CH, Huang MH, Chen TW, et al. Relationship between ankle position and pelvic floor muscle activity in female stress urinary incontinence. Urology 2005;66:288-92.

30. Chen HL, Lin YC, Chien WJ, et al. The effect of ankle position on pelvic floor muscle contraction activity in women. J Urol 2009;181:1217-23.

31. Kannan P, Fung B , Leung R, et al. Association between high-heeled shoes of varied heel height and bladder neck elevation in women: an exploratory study. Footwear Science 2019;11:85-92.

32. Ko DY, Lee HS. The Changes of COP and Foot Pressure after One Hour's Walking Wearing High-heeled and Flat Shoes. J Phys Ther Sci 2013;25:1309-12.

33. Lee M, Min S, Yoon S. The Evaluation of Stability Affected by Various Foot Clearance and Heel Type. JESK 2009;11:54-7.

34. Vitton V, Luciano L, Ortiz S, et al. Can wearing high heels influence anal canal pressure and the severity of fecal incontinence? Int Urogynecol J 2019;30:2049-54.

35. Frawley HC, Galea MP, Phillips BA, et al. Effect of test position on pelvic floor muscle assessment. Int Urogynecol J Pelvic Floor Dysfunct 2006;17:365-71.

(English Language Editor: C. Betlazar-Maseh) 